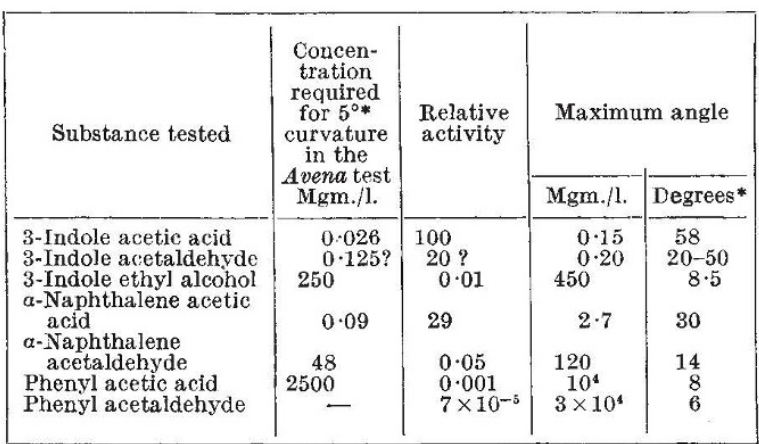

* $5^{\circ}$ curvature corresponds to a $d$-value of $0 \cdot 10$ ( $d$ is the difference in length between the inner and outer side of the curved coleoptile, measured in $\mathrm{mm}$.).

values are, of course, uncertain ; the relative activity may be between 10 and 40. 3-Indole ethyl alcohol (tryptophol) and $\alpha$-naphthalene acetaldehyde were prepared by Dr. K. A. Jensen. These substances, as well as phenyl acetaldehyde, were freed from possible traces of acid substances by shaking ethereal solutions with alkaline water immediately before the test; phenyl acetaldehyde was redistilled before shaking. As $5^{\circ}$ curvature is near the maximum angle produced by the latter substance, its relative activity was calculated on the basis of $3^{\circ}$ curvature. In the table are also shown the maximum angles for the compounds tested and the concentration needed for maximum curvature.

Other workers (using water-cultured test plants) found the relative activities of alpha-naphthalene acetic acid and phenylacetic acid to be $2 \cdot 5$ and 0.02 , respectively (compare Veldstra's list ${ }^{2}$ ). These values do not agree with those given here, obtained on soilgrown plants. This discrepancy may be due to the different methods of cultivating the test plants.

3 -Indole acetaldehyde could be oxidized to 3 -indoleacetic acid by treatment either with raw milk, with a purified Schardinger enzyme preparation (aldehydrase) or with soil. By soil treatment the activity of the aldehyde preparations was increased about 2.5 times. Soil treatment of indole ethyl alcohol and of alpha-naphthalene acetaldehyde preparations increased their activities by 100 and 20 times, respectively, indicating that these compounds are also oxidized by the soil, with the formation of the much more active acids.

Laboratory of Plant Physiology,

Poul Larsen

University of Copenhagen.

March 17.

${ }^{1}$ Larsen, Poul, thesis, Copenhagen. Dansk. Bot. Arkiv., 11, No. 9 $132(1944)$.

2 Veldstra, H., Enzymol., 11, 97 (1944).

\section{Molecular Weight of Melanin}

A METHOD of obtaining protein macro-molecules in crystalline form by the use of heparin has been described by Cohen ${ }^{1}$. As melanin is generally believed to have a high molecular weight, an attempt has been made to crystallize it by Cohen's method, using ethylene chlorhydrin as solvent. Heparin is not soluble to any appreciable extent in pure ethylene chlorhydrin; but both it and melanin are soluble in a mixture of equal parts of water and ethylene chlorhydrin. 'Dopa' and Sepia melanin have been used, with concentrations of heparin of $1,2,5$, and 10 per cent, with and without addition of electrolyte (sodium chloride), at temperatures varying from $-20^{\circ}$ to $20^{\circ} \mathrm{C}$. The attempt has failed completely, no precipitate being observed under any conditions even after standing for seven days.

It was observed by Cohen that although a number of highly complex proteins were precipitated by this method, those of comparatively low molecular weight, for example, gelatin, edestin and pepsin, did not respond, even with concentrations of heparin up to 10 per cent. This suggests, though by no means proves, that the molecule of melanin may not be so large as has been supposed. Further work at present in progress tends to support this view.

The work has been carried out with the aid of a grant from the Government Grant Committee of the Royal Society.

Medical Services,

A. J. LEA

Ministry of Pensions,

Norcross, Blackpool. March 16.

${ }^{1}$ Cohen, S. S., J. Biol. Chem., 144, 353 (1942).

\section{Free Radicals from Benzyl Hyponitrite}

$\mathrm{WE}_{\mathrm{E}}$ have recently prepared benzyl hyponitrite by the method of Partington and Shah ${ }^{1}$, and have found that it readily catalyses the polymerization of methyl methacrylate at room temperatures. At $30^{\circ} \mathrm{C}$. the rate of polymerization of methyl methacrylate initiated with benzyl hyponitrite is approximately thirty times as fast as the rate observed with an equal amount of benzoyl peroxide.

The polymerization of this monomer is known to be initiated by free radicals, and the benzyl hyponitrite must therefore produce free radicals by decomposition. By analogy with other compounds containing the $-\mathrm{N}=\mathrm{N}-$ group which are sources of free radicals, it is probable that benzyl hyponitrite decomposes into two benzoxy radicals $\mathrm{C}_{6} \mathrm{H}_{5} \mathrm{CH}_{2} \mathrm{O}-$ with the elimination of nitrogen. The formation of benzaldehyde and benzyl alcohol in presence of water reported by Partington and Shah could then be due to disproportionation of these benzoxy radicals.

\section{IVAN HARRIS}

IAN MARShaLI

KENNETH BARRY JARRETT

Research Department,

Imperial Chemical Industries Ltd., Plastics Division, Tewin Road, Welwyn Garden City.

${ }^{1}$ Partington and Shah, J. Chem. Soc., 2589 (1932).

\section{Addition of Dinitro Compounds to D.D.T. to Prevent Outbreak of Spider Mites}

IT is frequently observed that the use of sprays containing D.D.T. on fruit trees leads to a severe outbreak of Tetranychid mites or red spiders. In the United States, for example, Tetranychus pacificus $\mathrm{McG}$., Paratetranychus pilosus C. \& F. and P. citri $\mathrm{McG}$. have all been found to increase very considerably after D.D.T.-spraying has killed the predaceous insects which normally keep them under control. Research workers who have obtained excellent control of codling moth (Cydia pomonella L.) or other pests with D.D.T. have felt unable to recommend its general use owing to the risk of producing a severe mite infestation. It may therefore be of interest to record a method by which this difficulty was over. 